Teresa Cordes

Die Redeszenen in Chrétiens Chevalier de la Charrete, in Ulrichs Lanzelet und im Prosalancelot 


\section{Historische Dialogforschung}

Herausgegeben von

Nine Miedema, Angela Schrott

und Monika Unzeitig

\section{Band 4}




\section{Teresa Cordes}

\section{Die Redeszenen in Chrétiens Chevalier de la Charrete, in Ulrichs Lanzelet und im Prosalancelot}

Eine narratologische und sprachpragmatische Untersuchung 
ISBN 978-3-11-049087-9

e-ISBN (PDF) 978-3-11-049201-9

e-ISBN (EPUB) 978-3-11-049102-9

ISSN 2363-8001

\section{Library of Congress Cataloging-in-Publication Data}

A CIP catalog record for this book has been applied for at the Library of Congress.

\section{Bibliografische Information der Deutschen Nationalbibliothek}

Die Deutsche Nationalbibliothek verzeichnet diese Publikation in der Deutschen National-

bibliografie; detaillierte bibliografische Daten sind im Internet über http://dnb.dnb.de abrufbar.

(C) 2016 Walter de Gruyter GmbH, Berlin/Boston

Umschlagabbildung: Heinrich von Veldeke, Eneasroman, Abb. fol. 69r @ Dr. Ludwig Reichert Verlag, Wiesbaden

Druck und Bindung: CPI books GmbH, Leck

$\otimes$ Gedruckt auf säurefreiem Papier

Printed in Germany

www.degruyter.com 